from $20^{\prime \prime}$ to $40^{\prime \prime}$ on the plate, and without stellar nucleus. A short tail was suspected. - 2) Poor because of objectiv being frosted. - 3) The comet was Dec. 6 of about $9^{\mathrm{m}}$, the nucleus of about $13^{\mathrm{m}}$.

Mittlere Örter der. Vergleichsterne.

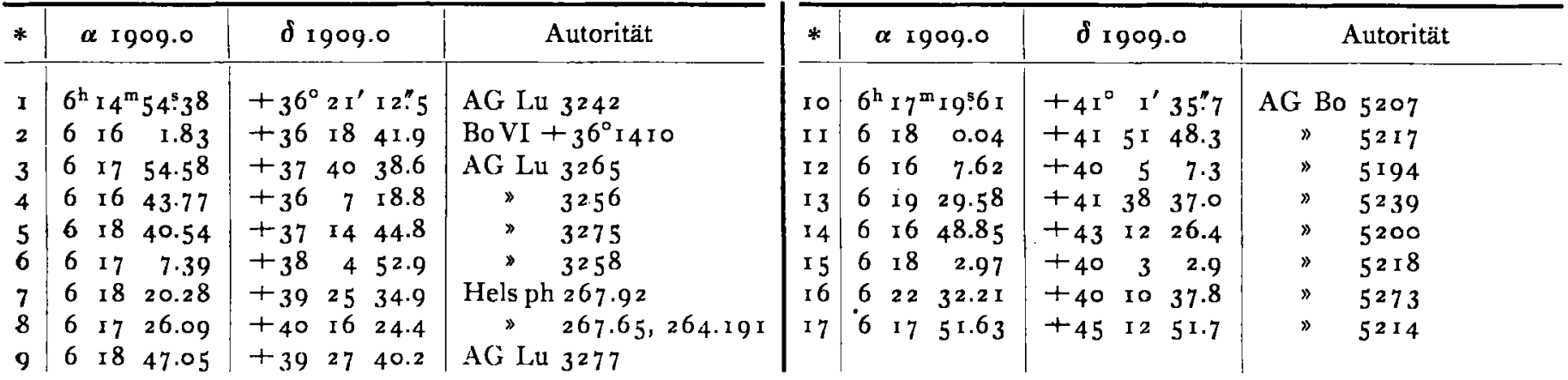

\title{
Mitteilung über ein am 16. November 1909 beobachtetes Meteor.
}

$\mathrm{Um}$ I $0^{\mathrm{h}} \mathbf{3 2}^{\mathrm{m}}$ (mitteleuropäische Zeit) abends den 16 . November I 909 habe ich in Hellerup (einer Vorstadt Kopenhagens) ein großes Meteor beobachtet. Wenn auch meine Angaben über die scheinbare Bahn des Körpers, dessen Erscheinung mich völlig überraschte, nach der Natur der Sache ziemlich unsicher sein werden, dürfte der wichtigste 'Teil meiner Beobachtung - in Bezug auf Form und Farbe des Meteors - doch keinem Zweifel unterworfen sein.

Das Meteor schien aus einem Ort etwa zwischen $\xi$ und $\gamma$ Draconis $z u$ kommen und bewegte sich in einer schwach gekrümmten Bahn in der Richtung nach I 7 Draconis, oder vielleicht etwas südlicher. Die Länge der sichtbaren Bahn war ungefähr $20^{\circ}$ und wurde ziemlich langsam (in etwa $3^{\mathrm{s}}$ ) zurückgelegt. Der Kopf des Meteors war glänzend weiß; nach kurzer Zeit entwickelte sich ein Schweif, dessen Länge vielleicht drei- oder viermal das Quermaß des Kopfes betrug und welcher rot gefärbt war und sich sogleich in zwei Teile spaltete, so daß der Anblick sehr an die Zeichnungen des Kopfes des Donatischen Kometen erinnerte. Gleichzeitig mit der Entwicklung des Schweifes fing das Meteor an, eine oszillierende Bewegung auszuführen, bis es ohne Geräusch erlosch.

Über die scheinbare Größe der Feuerkugel ist es für mich sehr schwierig eine Angabe zu machen. Ich hätte das Meteor für eine Rakete halten können, falls nicht diese Annahme durch die Richtung, Langsamkeit und scheinbare Höhe des Phänomens absolut ausgeschlossen gewesen wäre; auch habe ich gehört, daß das Meteor auch von Valby aus (einem anderen entfernten Vororte Kopenhagens) gesehen worden ist.

Hellerup, I 909 Nor, I 9.

F. F. Steffensen.

\section{Neuer Veränderlicher 45.1909 Piscium.}

Bei der Vergleichung von photographischen Aufnahmen mit dem Blinkmikroskop habe ich einen veränderlichen Stern gefunden, dessen Position näherungsweise ist:

$$
\alpha=23^{\mathrm{h}} 55^{\mathrm{m}} 55^{\mathrm{s}} \delta=+5^{\circ} 54^{\prime} 0 \quad \text { (1900). }
$$

Es liegen folgende Aufnahmen ror:

\begin{tabular}{|c|c|c|c|c|c|c|}
\hline Platte & & Datum & & Expos.-Zeit & beo & b. Gr. \\
\hline ir. $55^{\mathrm{I}}$ & I 901 & Sept. & I 9 & $2^{h} 3^{6^{m}}$ & etwa & $14^{m} \cdot 5$ \\
\hline 174 & 1909 & " & I 6 & $25^{\mathrm{m}}$ & 》 & I 2.5 \\
\hline I 7.52 & 1909 & ע & 20 & $2^{\mathrm{h}} 36^{\mathrm{m}}$ & » & 12.5 \\
\hline
\end{tabular}

Zur leichteren Orientierung bei der Aufsuchung ist der Veränderliche nit seiner näheren Umgebung in nebenstehendes $\mathrm{Kärtchen}{ }^{1}$ ) eingezeichnet, welches außerdem noch die Sterne der BI? enthält:

München, I go9 Dez. I 3 .

$$
\begin{aligned}
& \mathrm{BD}+5^{\circ} 5^{247} \quad 23^{\mathrm{h}} 5^{6^{\mathrm{n} 1}} 5^{5} .98+6^{\mathrm{o}} 14^{\prime} 5^{\prime \prime 6} \quad \text { (1900) } \\
& \mathrm{BD}+5^{\circ} 5^{2} 5^{2} \quad 2357 \text { 16.77 }+54^{6} 40.0 \text { (1900) }
\end{aligned}
$$

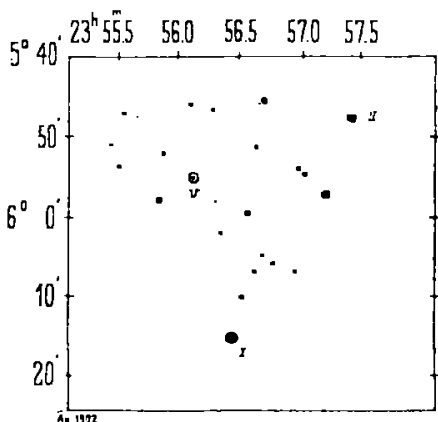

Dr. E. Silbernagel.

1) Die photogr. Himmelskarte Toulouse $+5^{\circ} \mathrm{Nr}$. 180 von 1899 Nov. $49^{\mathrm{h}} 28^{\mathrm{m}}$ Toulouse enthält an dieser Stelle nicht so schwache Sterne. $K b$. 